\title{
Atendimento Educacional Especializado: um dispositivo pedagógico na oportunização de acesso, recursos e desenvolvimento aos alunos público-alvo da educação especial
}

\author{
Raquel Bobsin Strasburg ${ }^{1}$ \\ Mônica Grazieli Marquet ${ }^{2}$ \\ Lidiane Barreto Alves Zwick ${ }^{3}$ \\ Isabella Fortes Boeira ${ }^{4}$ \\ Claudio Roberto Baptista ${ }^{5}$
}

\begin{abstract}
Resumo:
O presente artigo apresenta a possibilidade de ampliar o debate sobre a educação na perspectiva inclusiva de forma a problematizar como se organiza o Atendimento Educacional Especializado (AEE). O objetivo é analisar o AEE como dispositivo pedagógico descentralizado da sala de recursos para que ocorra em todos os espaços da escola. Trata-se de uma perspectiva que se opõe à compreensão restrita às práticas educacionais em sala de recursos e que valoriza a pluralidade prevista no plano das proposições e diretrizes políticas. A pesquisa foi realizada a partir de abordagem qualitativa, de cunho bibliográfico, envolvendo produções que abordam as discussões sobre a temática proposta. O estudo tem como referencial teórico o ciclo de políticas formulado por Stephen Ball e Richard Bowe para pensar em como as políticas de inclusão escolar agem no contexto da prática. Além dessa perspectiva, a análise contempla o pensamento sistêmico de Gregory Bateson e a tríade "contexto-processo-relações". As reflexões apresentadas ampliam as formas de configurações do AEE por meio de uma atuação sistêmica do professor de educação especial e uma articulação entre os diferentes profissionais da escola. Desse modo, compreende-se o trabalho compartilhado como possibilidade de romper a lógica da padronização dos processos de ensino.
\end{abstract}

\section{Palavras-chave:}

Educação especial. Atendimento educacional especializado. Dispositivo pedagógico. Ensino colaborativo. Políticas de inclusão escolar.

\footnotetext{
1 Mestranda no Programa de Pós-Graduação em Educação/UFRGS. Professora de Educação Especial nas redes municipais de ensino de Capão da Canoa/RS e Xangri-lá/RS. E-mail: raquelstrasburg@hotmail.com. ORCID iD: http://orcid.org/0000-00029032-8039.

2 Doutoranda no Programa de Pós-Graduação em Educação/UFRGS. Professora de Educação Especial na rede municipal de ensino de Capão da Canoa/RS. E-mail: monimarquet@gmail.com. ORCID iD: http://orcid.org/0000-0002-7813-7790.

3 Mestra em Educação no Programa de Pós-Graduação em Educação/UFRGS. Tradutora/intérprete de Libras do IFRS - Campus Osório. E-mail: lidiane.alves@osorio.ifrs.edu.br. ORCID iD: http://orcid.org/0000-0001-8146-7929.

4 Graduanda em Licenciatura em Letras - Língua Portuguesa e Literaturas de Língua Portuguesa, Língua Inglesa e Literaturas de Língua Inglesa. E-mail: isabellafortes_@hotmail.com. ORCID iD: http://orcid.org/0000-0002-4425-370X.

5 Doutor em Educação e Docente do Programa de Pós-Graduação em Educação da Universidade Federal do Rio Grande do Sul. E-mail: baptistacaronti@yahoo.com.br. ORCID iD: http://orcid.org/0000-0001-6673-4574.
} 


\title{
Specialized Educational Care: a pedagogical device in the opportu- nity for access, resources and development to students targeted by special education
}

\begin{abstract}
:
This paper presents the possibility of expanding the debate on education from an inclusive perspective, to problematize how Specialized Educational Service (SES) is organized. The objective is to analyze the SES as a decentralized pedagogical device of the resource room to occur in all spaces of the school. It is a perspective that opposes the understanding restricted to educational practices in the resource room and that values the plurality provided for in the plan of political propositions and guidelines. The research was carried out from a qualitative, bibliographic approach, involving productions that address the discussions on the proposed theme. The study has as theoretical reference the policy cycle formulated by Stephen Ball and Richard Bowe to think about how school inclusion policies act in the context of practice. In addition to this perspective, the analysis contemplates Gregory Bateson's systemic thinking and the triad of "context-process-relationships." The reflections presented expand the forms of SES configurations through a systemic performance of the special education teacher and an articulation between the different professionals of the school. Thus, shared work is understood as a possibility to break the logic of standardization of teaching processes.
\end{abstract}

\section{Keywords:}

Special education. Specialized educational service. Pedagogical device. Collaborative teaching. School inclusion policies.

\section{Atención Educativa Especializada: un dispositivo pedagógico para brindar acceso, recursos y desarrollo a los estudiantes público objetivo de la educación especial}

\section{Resumen:}

El artículo presenta la posibilidad de ampliar el debate sobre la educación desde una perspectiva inclusiva con el fin de problematizar cómo se organiza la Atención Educativa Especializada (AEE). El objetivo es analizar la AEE como un dispositivo pedagógico descentralizado de la sala de recursos, para que ocurra en todos los espacios de la escuela. La investigación se realizó desde un enfoque cualitativo de tipo bibliográfico, involucrando producciones que abordan discusiones sobre el tema propuesto; se trata de una perspectiva que se opone a la comprensión restringida de prácticas educativas en la sala de recursos y que valora la pluralidad prevista en el plan de proposiciones y directrices políticas. El estudio tiene como marco teórico el ciclo político formulado por Stephen Ball y Richard Bowe que permite pensar cómo actúan las políticas de inclusión escolar, además el análisis contempla el pensamiento sistémico de Gregory Bateson y la tríada de "contexto-proceso-relaciones". Las reflexiones presentadas amplían las configuraciones de la AEE a través de una actuación sistémica del profesor de educación especial y una articulación entre los diferentes profesionales de la escuela, se comprende así el trabajo compartido como posibilidad de romper la lógica de estandarización de los procesos educativos.

Palabras clave:

Educación especial. Atención educativa especializada. Dispositivo pedagógico. Enseñanza colaborativa. Políticas de inclusión escolar. 


\section{Introdução}

Nos últimos trinta anos, tem ocorrido um fortalecimento da perspectiva educacional inclusiva com a ampliação das normativas que dizem respeito à escolarização das pessoas com deficiência no âmbito das escolas brasileiras. Contudo, ainda é necessária uma ampliação do debate sobre essas diretrizes e suas respectivas ações no sentido de qualificar a organização das práticas pedagógicas instituídas nesses espaços educacionais.

Embora perceba-se a ocorrência de avanços na organização dos serviços, ao deslocarmos nossas lentes para o ano de 2021, consideramos a possibilidade de problematizar a forma como se organiza o Atendimento Educacional Especializado (AEE), que atualmente tem como lócus prioritário a sala de recursos. Consideramos que esta proposta ainda tenha alguns aspectos que a aproximam de uma perspectiva clínico-terapêutica. Identificamos a necessidade de avançarmos nas discussões, problematizações e possibilidades de pensarmos sobre uma proposta de AEE descentralizando a atuação do professor de educação especial que considere a sala de aula comum como espaço prioritário de escolarização. Assim, buscamos como objetivo geral deste trabalho analisar uma reconfiguração da oferta do AEE - AEE como um dispositivo pedagógico - considerando que este ocorra de forma descentralizada, sendo ofertado em todos os espaços escolares. Nesse sentido, definimos como objetivos específicos deste trabalho: apresentar um percurso histórico dos direcionamentos normativos da educação especial; caracterizar o AEE como dispositivo pedagógico definindo a amplitude das ações desse serviço; sinalizar as diferentes configurações e ações que esse serviço pode assumir, evidenciando barreiras e possibilidades de avanços a partir dessa prática.

\section{Metodologia}

Buscando discutir o campo de análise de políticas públicas, considerando o caráter complexo, dinâmico e singular que envolve as políticas de inclusão escolar, tomamos como referencial teórico-analítico o ciclo de políticas formulado por Stephen Ball e Richard Bowe e o pensamento sistêmico de Gregory Bateson. Essa abordagem nos permite pensar as múltiplas formas de atribuição de sentidos e as distintas possibilidades de reinterpretação das políticas e seus movimentos no contexto da prática. Segundo Ball (1994), as políticas são formuladas mediante embates, acordos, interpretações e reinterpretações por parte dos grupos de interesse, sendo decodificadas também de maneira complexa pela interpretação desses atores, atribuindo significados que variam em relação a suas histórias, experiências e possibilidades. É atribuído à política um caráter de texto e discurso. Conforme Mainardes,

[...] o foco da análise de políticas deveria incidir sobre a formação do discurso da política e sobre a interpretação ativa que os profissionais que atuam no contexto da prática fazem para relacionar os textos da política à prática. (MAINARDES, 2006, p. 50).

Essa abordagem permite uma análise crítica e contextualizada das políticas educacionais, considerando o processo de sua formulação até a sua implementação no contexto da prática, bem como os seus resultados/efeitos.

O pensamento sistêmico afirma-se como uma perspectiva que considera as dimensões imbricadas na tríade "contexto-processo-relações" envolvendo os seres vivos e o ambiente no qual estamos inseridos. Considera que somos parte dos movimentos recursivos que apontam para transformações congruentes (PISTÓIA, 2009, p. 3). Essa perspectiva nos permite pensar a complexidade dos processos, ampliando o foco da análise que, frequentemente, tem como centro os elementos individuais para as relações, considerando, portanto, o sujeito em contexto 
(VASCONCELLOS, 2013). Pensar com base nessa perspectiva nos direciona a considerar o estado de inter-relação e interdependência essencial de todos os fenômenos: físicos, biológicos, psicológicos, sociais e culturais (PISTÓIA, 2009). Desse modo, tendo como referência uma dinâmica de múltiplas interdependências, a análise nos possibilita entender os processos políticos. Considera-se que essa pluralidade constitutiva dos fenômenos está na origem dos fenômenos investigados e que ela deveria também ser considerada quando pensamos em formas de intervenção. Morin (2007) discorre que o pensamento sistêmico é um pensamento fundante, baseado em um conhecimento complexo sobre a palavra sistema. O sistema não é simplesmente um todo constituído de partes, suas qualidades e propriedades não existem no nível das partes isoladas, ou seja, o todo é mais que a soma das partes. Assim, se aproxima das ideias de Bateson (1986, p. 23), que reforça que "[...] sem contexto, palavras e ações não têm qualquer significado [...]"; vinculados a esses pressupostos, buscamos estabelecer reflexões sobre o contexto dos processos analisados.

O percurso estabelecido no decorrer do trabalho busca contemplar os objetivos geral e específicos. Para tanto, utilizamos como procedimento metodológico uma pesquisa de abordagem qualitativa, de cunho bibliográfico, considerando produções que abordam a temática proposta. Indicamos que esta discussão nos permite evidenciar um debate atual que versa sobre possíveis redirecionamentos, interpretações e reinterpretações da implementação de políticas públicas que instituem o AEE.

\section{Percursos normativos: interfaces na constituição de uma proposta educacional inclusiva}

Para refletir sobre o sistema educacional inclusivo e sobre as atuais perspectivas de ação pedagógica, destacamos algumas normativas e diretrizes que orientam as concepções de trabalho frente à educação especial em nível internacional e nacional. A seguir, apresentam-se momentos de referência nesta construção, identificando o processo constitutivo das legislações de referência que possibilitam compreender o atual contexto dos serviços oferecidos pela educação especial, finalizando com a proposição de uma releitura dos direcionamentos, com ênfase no AEE, considerando essa possibilidade de trabalho: AEE como dispositivo pedagógico.

Como marco de referência inicial para nossas discussões, tomamos a Conferência Mundial sobre Educação para Todos (UNESCO, 1990), a qual reafirma o direito de todos à educação, como fundamento de determinação individual e coletiva.

A Declaração de Salamanca (UNESCO, 1994) expõe aspectos que se constituem como base para uma escola na perspectiva inclusiva, propondo princípios gerais da educação como o direito de toda criança à escolarização e oportunidade de atingir níveis adequados de aprendizagem, o respeito às diferentes características, interesses, habilidades e necessidades de aprendizagem, considerando que todos apresentam essas características de forma individual. De modo singular, todos aprendem.

Em âmbito nacional, temos a proposição da Política Nacional de Educação Especial (BRASIL, 1994) que se instituiu como documento orientador, anunciando um conjunto de objetivos destinados a garantir o atendimento educacional aos alunos com deficiência, propondo a garantia do direito à igualdade de oportunidades. Essa política buscou inspirar a elaboração de planos de ação atribuindo responsabilidade aos órgãos públicos e às entidades não governamentais. Fundamenta-se na Constituição Federal de 1988 (BRASIL, 1988), a partir da qual a educação é concebida como direito de todos e dever do Estado.

A lei no 9.394/96, que estabelece a Lei de Diretrizes e Bases da Educação Brasileira (LDB) com princípios gerais, retoma, em seu artigo $3^{\circ}$, inciso I, sobre a igualdade de condições de acesso, além de incorporar um capítulo específico sobre a educação especial. O capítulo V apresenta 
vários elementos que indicam o atendimento dos estudantes público-alvo da educação especial ${ }^{6}$ na rede regular de ensino. Dentre esses, destacamos que o poder público sinaliza a ampliação dos atendimentos com enfoque em currículo, métodos, técnicas, recursos e organização específica em espaços de ensino comum (BRASIL, 1996).

Em 2003, a Secretaria de Educação Especial (SEESP) do Ministério da Educação deu início à implementação do Programa Educação Inclusiva: direito à diversidade, o qual se apresenta como uma expressão de uma política que busca auxiliar na mudança de mentalidade, investindo em formação continuada de gestores e educadores, objetivando oferecer capacitação em educação especial na perspectiva da educação inclusiva nas redes municipais e estaduais de ensino por meio de um sistema de formação com base em uma rede de multiplicadores (BRASIL, 2003).

Em busca de apoiar a organização e a oferta do AEE, oferecido de forma complementar ou suplementar aos estudantes público-alvo da educação especial matriculados em classes comuns do ensino regular, é criado, em 2007, o programa Implementação de Salas de Recursos Multifuncionais, o qual disponibiliza a estas instituições um conjunto de equipamentos para oferta deste serviço.

As diretrizes instituídas pela Política Nacional de Educação Especial na Perspectiva da Educação Inclusiva (PNEEPEI) indicam que a educação especial passa a ser compreendida como "[...] uma modalidade de ensino que perpassa todos os níveis, etapas e modalidades" (BRASIL, 2008, p. 8), tendo o AEE como parte constituinte do processo educacional. Dessa forma, os sistemas de ensino passam a se organizar ofertando o AEE nas escolas de ensino comum. "Esse atendimento complementa e/ou suplementa a formação dos alunos com vistas à autonomia e independência na escola e fora dela" (BRASIL, 2008, p. 16). Trata-se de uma dinâmica que, por meio da busca de garantia do apoio ao ensino comum, busca a redução sistemática do investimento em espaços exclusivos de escolarização como classes e escolas especiais.

Ratificando as diretrizes da Convenção Internacional sobre os Direitos das Pessoas com Deficiência da Organização das Nações Unidas (ONU, 2006), o Decreto nº 6.949/2009 (BRASIL, 2009a) tem como efeito a incorporação do texto dessa Convenção, com status de emenda constitucional, reafirmando os direitos das pessoas com deficiência à educação em espaços de ensino comum. Esse documento apresenta de forma contundente o direito das pessoas com deficiência à educação, sem discriminação e com base na igualdade de oportunidades, e determina que essas não sejam excluídas do sistema educacional geral sob a alegação de sua deficiência, não deixando margem para exceções baseadas nas supostas limitações dos sujeitos.

Versando sobre a educação especial e o AEE, o Decreto n 7.611/2011 (BRASIL, 2011), em seu Art. $1^{\circ}$, inciso I, também sinaliza a "garantia de um sistema educacional inclusivo em todos os níveis, sem discriminação e com base na igualdade de oportunidades".

A Lei no 13.146 (BRASIL, 2015), que institui a Lei Brasileira de Inclusão da Pessoa com Deficiência (LBI), em seu Art. 1\%, orienta "[...] assegurar e a promover, em condições de igualdade, o exercício dos direitos e das liberdades fundamentais por pessoa com deficiência, visando à sua inclusão social e cidadania" (BRASIL, 2015, p. 1).

Observar os textos dessas normativas é uma iniciativa que nos permite pensar contextualmente como esses períodos históricos refletem na modalidade de ensino da educação especial, nos conceitos, nos espaços da oferta de um serviço educacional, definindo os contornos da modalidade educação especial e, principalmente, suas perspectivas. Contudo, abordar esses temas implica o reconhecimento relativo aos avanços e aos retrocessos observados ao longo das últimas décadas - o que nos instiga a refletir sobre a seguinte problemática: como o serviço de AEE tem se organi-

6 De acordo com o Decreto $n^{\circ} 7611$, de dezessete de novembro de 2011 (BRASIL, 2011), considera-se como público-alvo da educação especial as pessoas com deficiência, com transtornos globais do desenvolvimento e com altas habilidades ou superdotação. 
zado atualmente no que se refere à configuração de trabalho pedagógico, de seu espaço e de sua abordagem?

Passamos a estabelecer uma aproximação entre os aspectos apresentados com a identificação da problemática deste trabalho. Toma-se como marco de referência o ano de 2008 para sinalizar dois diferentes momentos: o primeiro centrado no modelo clínico-terapêutico e o segundo, no modelo social da deficiência.

Historicamente, a configuração da oferta de ensino associado à educação especial esteve baseada no modelo clínico-terapêutico, que identificava a causa das barreiras e dos impedimentos como se estes fossem intrínsecos aos sujeitos com deficiência. A ideia predominante é que este sujeito deveria ser "corrigido" para então ser inserido no contexto social e educacional. Dessa forma, eram oferecidos para escolarização desses sujeitos, espaços segregados, que visavam a um atendimento exclusivo e substitutivo: as escolas especiais e as classes especiais. As classes comuns do ensino regular eram organizadas, simplificadamente, com base na pressuposição de turmas homogêneas, com uma tendência à padronização do processo de ensino aprendizagem. Esse processo deixava os alunos público-alvo da educação especial à margem dessa proposta de escolarização.

A partir de 2008, com base na aprovação da PNEPEEI, que pode ser considerada um marco no processo histórico das políticas de educação especial no Brasil, ocorre a intensificação de ações decorrentes de diretrizes favorecedoras da inclusão escolar. Acontece um significativo aumento do número de matrículas de alunos público-alvo da educação especial na rede regular de ensino. Podemos observar no gráfico a seguir o movimento inverso frente ao quantitativo de matrículas com referência às classes comuns e classes especiais, com a identificação de um aumento constante e significativo de matrículas no ensino regular.

Gráfico 1 - Quantitativo de matrículas dos alunos público-alvo da educação especial em classes comuns e classes exclusivas no Brasil - 2008 a 2020

\subsection{0 .000}

1.200 .000

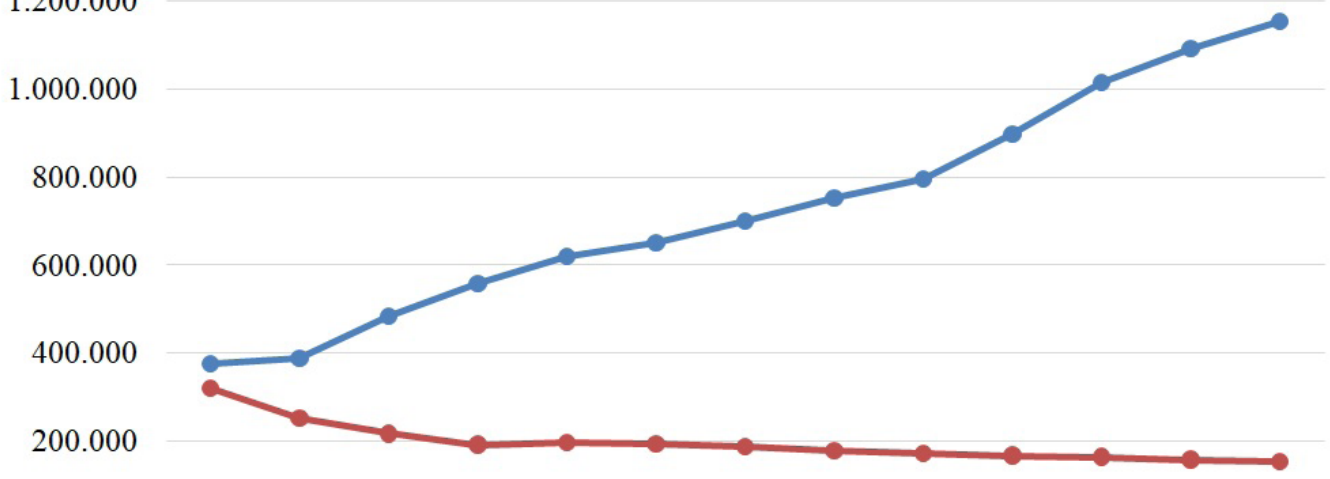

0

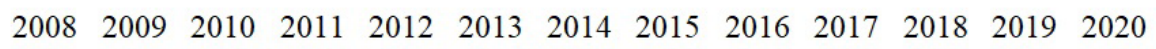

$\multimap$ Classes Comuns $\longrightarrow$ Classes Exclusivas

Fonte: Elaborado pelos autores ${ }^{7}$.

A PNEPEEI reafirmou a defesa da escolarização das pessoas com deficiência sugerindo uma nova abordagem conceitual, com um afastamento de uma perspectiva clínico-terapêutica e

7 Dados de 2008 a 2019 coletados nas sinopses estatísticas e dados de 2020 coletados no Censo Escolar da Educação Básica do INEP/ MEC/DEED. 
valorizando as discussões relativas ao modelo social da deficiência, que, de acordo com a definição de Bampi, Guilherm e Alves (2010), desloca as desvantagens anteriormente caracterizadas como intrínsecas ao indivíduo para as relações estabelecidas socialmente.

Entre o modelo social e o modelo médico há diferença na lógica de causalidade da deficiência. Para o modelo social, a sua causa está na estrutura social. Para o modelo médico, no indivíduo. Em síntese, a ideia básica do modelo social é que a deficiência não deve ser entendida como um problema individual, mas uma questão da vida em sociedade, o que transfere a responsabilidade pelas desvantagens das limitações corporais do indivíduo para a incapacidade da sociedade em prever e se ajustar à diversidade. (BAMPI; GUILHERM; ALVES, 2010, p. 2-3).

Assim, direciona-se a compreensão de que a causa das barreiras e dos impedimentos está associada à relação entre a pessoa com deficiência e o meio em que está inserida.

Essa mudança de perspectiva favorece que as classes de ensino comum, que estiveram fortemente centradas na homogeneidade, passassem a ser reconhecidas como um espaço plural marcado pelas diferenças constitutivas de seus integrantes, sejam eles alunos com deficiência ou com outras singularidades. As normativas nacionais e os programas ministeriais passaram a direcionar recursos para disponibilizar a implementação de sala de recursos multifuncionais, sendo este o espaço considerado prioritário para a oferta do AEE com carácter de atendimento complementar ou suplementar, de forma a apoiar a organização do ensino e a presença do estudante com deficiência em classe comum.

Como tentativa de enfatizar que esse atendimento não seja substitutivo, a Resolução $n^{\circ} 4$, de 2009, do CNE/CEB (BRASIL, 2009b), em seu artigo 5º, sinaliza o contraturno como momento ideal para sua realização. Embora seja possível entender a importância desse direcionamento, naquele momento específico, como forma de evitar a retirada do aluno da sala de aula comum, ocorre uma proposição que intensifica o trabalho de apoio especializado em um espaço de atendimento específico, a sala de recursos. Esse direcionamento deixa margem para a necessidade de ampliarmos a compreensão sobre o espaço prioritário de escolarização dos estudantes público-alvo da educação especial, pois é recorrente, em âmbito escolar, a sinalização da sala de recursos como um espaço central destinado a esse aluno, no qual contaria com atenção de um profissional especializado detentor do suposto conhecimento e de práticas que "ajustariam" o aluno aos padrões de aprendizagem pré-estabelecidos tradicionalmente. Como é possível perceber, apesar da intensidade dos novos investimentos na oferta do apoio especializado, corre-se o risco de concentrar as ações e a própria escolarização em espaço distinto da classe comum.

\section{AEE como dispositivo pedagógico: caracterizando conceitos}

A partir dessa abordagem histórica que sinaliza avanços nas discussões relativas à educação na perspectiva inclusiva, há a necessidade de aprofundar a caracterização do serviço de AEE e de identificar seus direcionamentos nas normativas nacionais. A PNEEPEI (BRASIL, 2008) institui o objetivo de:

[...] assegurar a inclusão escolar de alunos com deficiência, transtornos globais do desenvolvimento e altas habilidades/superdotação, orientando os sistemas de ensino para garantir: acesso ao ensino regular, com participação, aprendizagem e continuidade nos níveis mais elevados do ensino. (BRASIL, 2008, p. 14). 
Como forma de instituir esse direcionamento político, as diretrizes operacionais para o AEE na educação básica preveem a disponibilização de "[...] recursos de acessibilidade e estratégias que eliminem as barreiras para sua plena participação na sociedade e desenvolvimento de sua aprendizagem" (BRASIL, 2009b, p. 1). É possível pressupor que, ao apresentar a indicação de práticas que "eliminem as barreiras", a PNEEPEI parte da consideração de que há um contexto que pode atuar como intensificador das limitações no caso de não investimento desse processo de eliminação das barreiras. Trata-se de uma perspectiva que permite que reconheçamos uma aproximação com o designado modelo social da deficiência.

Ao pensarmos sobre as barreiras encontradas no espaço escolar, identifica-se que podem estar atreladas a aspectos como: a inexistência de adequações arquitetônicas, barreiras atitudinais e conceituais, resultando na dificuldade ou mesmo limitando o acesso às possibilidades de participação e de desenvolvimento. Esse entendimento permite que seja atribuída à escola a responsabilidade de repensar e reorganizar as ações pedagógicas, considerando a diversidade de seus alunos.

A resolução no 04/2009 (BRASIL, 2009b), em seu artigo 4º define os estudantes público-alvo da educação especial beneficiados pelo AEE no contexto escolar. A partir dessa definição, a oferta do AEE passa a ser obrigatória aos estudantes, mas ressalta-se, na disposição da Nota Técnica 04/2014 (BRASIL, 2014), a não obrigatoriedade do laudo médico-clínico para definir o acesso do estudante ao serviço.

O importante é que o direito das pessoas com deficiência à educação não poderá ser cerceado pela exigência de laudo médico. A exigência de diagnóstico clínico dos estudantes com deficiência, transtornos globais do desenvolvimento, altas habilidades/superdotação, para declará-lo, no Censo Escolar, público alvo da educação especial e, por conseguinte, garantir-lhes o atendimento de suas especificidades educacionais, denotaria imposição de barreiras ao seu acesso aos sistemas de ensino, configurando-se em discriminação e cerceamento de direito. (BRASIL, 2014, p. 3).

Com essa sinalização, coloca-se em evidência a dimensão pedagógica. Consideramos que as escolas deveriam cumprir seu papel de ensino favorecedor da aprendizagem, ampliando o público a ser atendido, garantindo um olhar acolhedor e movimentações dos professores para oportunizar ações que possibilitem a presença do desafio, a garantia de apoio quando necessário e a pluralidade de práticas, considerando a condição de cada sujeito e reafirmando o princípio da educabilidade de todos.

Assim, o AEE deve ser garantido aos estudantes público-alvo da educação especial com ou sem a presença de laudo médico definido, pois a prioridade deveria ser o parecer pedagógico que indica a necessidade de um apoio especializado. Porém, devido ao caráter facultativo desse atendimento, algumas famílias optam ou não se organizam para assegurar a frequência do aluno a esse serviço. De fato, é necessário que se reflita quanto à situação de que nem todos os alunos identificados como público-alvo da educação especial devam necessariamente frequentar a sala de recursos. Importante também destacar que o apoio especializado não se restringe, ou não deveria estar restrito, a esse espaço.

As orientações para o AEE em âmbito escolar são apresentadas na Resolução no 04/2009 (BRASIL, 2009b, p. 3), que, em seu artigo 13, normatiza as atribuições do professor de AEE.

I - identificar, elaborar, produzir e organizar serviços, recursos pedagógicos, de acessibilidade e estratégias considerando as necessidades específicas dos alunos público-alvo da Educação Especial;

II - elaborar e executar plano de Atendimento Educacional Especializado, avaliando a funcionalidade e a aplicabilidade dos recursos pedagógicos e de acessibilidade; 
III - organizar o tipo e o número de atendimentos aos alunos na sala de recursos multifuncionais;

IV - acompanhar a funcionalidade e a aplicabilidade dos recursos pedagógicos e de acessibilidade na sala de aula comum do ensino regular, bem como em outros ambientes da escola;

$\mathrm{V}$ - estabelecer parcerias com as áreas intersetoriais na elaboração de estratégias e na disponibilização de recursos de acessibilidade;

VI - orientar professores e famílias sobre os recursos pedagógicos e de acessibilidade utilizados pelo aluno;

VII - ensinar e usar a tecnologia assistiva de forma a ampliar habilidades funcionais dos alunos, promovendo autonomia e participação;

VIII - estabelecer articulação com os professores da sala de aula comum, visando à disponibilização dos serviços, dos recursos pedagógicos e de acessibilidade e das estratégias que promovem a participação dos alunos nas atividades escolares.

Percebe-se que os incisos I, II, III e VII da referida resolução direcionam o atendimento a ser realizado em espaço específico, sala de recursos, que regularmente se apresenta como o lócus de atendimento aos alunos público-alvo da educação especial. Mas os incisos IV, VI e VIII destacam uma prática pedagógica articulada a outros espaços escolares, afastando a ideia da existência de um espaço específico para o AEE. Temos ainda o inciso $\mathrm{V}$, que sinaliza a articulação com áreas intersetoriais, sugerindo a ideia de que o AEE pode extrapolar as paredes da escola.

Com a reflexão acerca da normativa, Baptista (2011) ressalta que devemos ampliar o debate contemporâneo relativo às diretrizes da educação especial, que possibilite desenvolver um trabalho sistêmico, reconhecendo a necessidade de refinamento da prática pedagógica buscando articulações com os recursos disponíveis aliados às condições de gestão. Baptista (2011) ainda complementa:

Embora tenhamos que admitir a grande amplitude das ações e a possibilidade interpretativa de práticas centradas no atendimento direto ao aluno, é necessário que se identifique a potencial valorização do trabalho compartilhado com outros profissionais, principalmente o docente do ensino comum [...]. (BAPTISTA, 2011, p. 65).

O trabalho articulado com outros profissionais em ambientes distintos possibilita ampliar as esferas de atendimento aos estudantes, descentralizando o serviço pautado a um profissional ou espaço restrito.

Essa importância respalda-se na centralidade da sala de recursos como o dispositivo pedagógico prioritário na política de Educação Especial contemporânea, considerada sua característica de não substituição do espaço da sala de aula comum para a escolarização. Além disso, as atribuições que implicam conexões/articulações entre o docente especializado e o professor do ensino comum abrem espaço para a discussão curricular necessária nos processos inclusivos. (BAPTISTA, 2011, p. 65).

A partir dessa reflexão, sugere-se que seja reafirmada uma interpretação da Resolução n ${ }^{\circ}$ 04/2009 (BRASIL, 2009b), sinalizando a amplitude do serviço e das atribuições do professor de educação especial, vinculando o serviço do AEE como um dispositivo pedagógico. Com base nessa perspectiva, o professor de educação especial atua em todos os espaços escolares, em cooperação com os profissionais envolvidos no processo de ensino aprendizagem, não se limitando ao atendimento em sala de recursos, ou ainda não concentrando suas ações exclusiva/unicamente com o aluno público-alvo da educação especial. Essa abordagem está em sintonia com a argumentação de Mendes (2006), que define o ensino colaborativo. 
Em síntese, o ensino colaborativo ou co-ensino, é um modelo de prestação de serviço de educação especial no qual um educador comum e um educador especial dividem a responsabilidade de planejar, instruir e avaliar a instrução de um grupo heterogêneo de estudantes, sendo que esse modelo emergiu como uma alternativa aos modelos de sala de recursos, classes especiais ou escolas especiais, e especificamente para responder às demandas das práticas de inclusão de estudantes com necessidades educacionais especiais. (MENDES, 2006, p. 32).

$\mathrm{Na}$ tentativa de colaborar com a proposição do AEE como dispositivo pedagógico, nos aproximamos da definição de dispositivo segundo Peixoto (2008):

[...] a noção de dispositivo se propõe a apreender as diferentes lógicas de uso e interação entre elementos heterogêneos que intervêm em sua implementação. O dispositivo sugere um lugar (espaço), um processo (tempo) e um "objeto comum" a ser negociado entre os sujeitos (social). Ele exige o questionamento constante do que está acontecendo (dimensão dinâmica) na instituição quanto a novas práticas (dimensão inovante) que substituem as anteriores, tão fixadas que parecem naturais. (PEIXOTO, 2008, p. 44-45).

Ao relacionar a organização do AEE com a definição de dispositivo referido pela autora, remete-se a pensar as diferentes lógicas desse serviço, os lugares (espaços), o processo (tempo) e um objeto comum (social) respectivamente: sala de recursos, o contraturno e o aluno. Esse movimento exige que se reflita sobre novas práticas (dimensão inovadora) e sobre a instituição de outras dinâmicas.

Caldeira, Oliveira e Araújo (2020), ao apresentarem uma pesquisa sobre a educação básica, salientando as dúvidas e incertezas presentes na escola regular sobre como efetivar práticas inclusivas e os desafios desse processo em uma escola de tempo integral, se aproximam de nossas discussões ao sinalizar os desafios presentes na organização da oferta do AEE na realidade de um Centro Pedagógico (CP) do Colégio de Aplicação da UFMG. Os desafios ao pensar o AEE, em tempo e espaço, nesta realidade específica, podem encontrar uma alternativa na proposta do AEE como dispositivo pedagógico. Acreditamos que o AEE, de acordo com esta configuração, pode constituir-se como base para o desenvolvimento de ações para efetivar o processo inclusivo também nas instituições de ensino integral.

Tão importante quanto pensar as questões estruturais e organizacionais no contexto escolar é observar os sujeitos envolvidos na prática pedagógica.

Um dispositivo de formação é constituído de um conjunto de atores (aprendizes, tutores, responsáveis pela formação) e de ferramentas técnicas organizadas no espaço e no tempo, de acordo com uma meta de aprendizagem. Dessa forma, o dispositivo de formação é em si mesmo mediação; por conseguinte, distribui papéis entre os atores, organiza a sua participação, suscita e define, pouco a pouco, a utilização real e ativa. O dispositivo é resultado de uma recomposição permanente, nascida de trocas, negociações, confrontações e, eventualmente, de polêmicas ou controvérsias. (PEIXOTO, 2008, p. 43-44).

Nessa perspectiva, o professor de educação especial atua também como articulador e mediador na formação e disseminação de uma mentalidade inclusiva, a partir de momentos formativos que promovem a possibilidade de trocas, de formação de conceitos e de repensar o percurso pedagógico.

O AEE como dispositivo pedagógico institui-se como um serviço dinâmico permeando todos os espaços escolares, em momentos diversos, em sala de recursos e articulando-se com o professor da sala de aula comum, num trabalho articulado, colaborativo e descentralizado. $\mathrm{O}$ trabalho realizado na sala de recursos deixa de ser o espaço prioritário de atendimento ao aluno 
público-alvo da educação especial, visto que o professor do AEE poderá ofertar esse serviço de forma contextual e descentralizada.

Haas (2013) discorre sobre o serviço de AEE, defendendo a possibilidade de este serviço ocorrer em diferentes espaços, não centrando-se na sala de recursos multifuncional como espaço prioritário para o atendimento. A autora ainda sinaliza que a proposição de uma única configuração ao AEE vem prevalecendo nos sistemas de ensino, porém sugere que sejam pensadas novas configurações:

[...] criar alternativas para oferta AEE, além da sala de recursos, seja em práticas pedagógicas de bidocência; em trabalho em pequenos grupos, em alguns momentos, com acompanhamento da professora especializada. Enfim, a Escola precisa repensar o AEE para atender às especificidades deste público, ao invés de insistir no discurso de que o público não está adequado à proposta do AEE. (HAAS, 2013, p. 82).

As possibilidades de organização pontuadas pela autora aproximam-se das proposições do AEE como um dispositivo pedagógico. Nessa direção, observa-se que o apoio especializado, dirigido aos alunos com deficiência, tende a ocorrer de forma descentralizada, em diferentes espaços.

A partir das abordagens aqui apresentadas, estabelecemos neste trabalho alguns parâmetros para considerar o AEE como dispositivo pedagógico:

» Uma prática descentralizada que contemple ações diversas, não se restringindo a um conjunto instrucional de procedimentos;

» atuação dinâmica em todos os espaços do ambiente escolar, contrariando a ideia de um trabalho limitado a um espaço específico (sala de recursos);

» valorização de uma ação mais sistêmica do profissional especializado, articulando com os professores de sala de aula regular, profissionais de apoio, família, serviço de orientação, de supervisão, de gestão etc.;

» professor de educação especial considerado um articulador, mediador e disseminador de uma mentalidade relacionada à perspectiva educacional inclusiva, entendendo que o eixo estruturante de seu trabalho não esteja restrito ao aluno com deficiência, mas ao contexto no qual este aluno está inserido.

Sinalizamos como barreiras possíveis de serem concebidas no processo desse trabalho de articulação, as resistências dos profissionais, as angústias frente às questões de acessibilidade ao currículo e as dificuldades de organização de carga horária. Tais barreiras podem estar fundamentadas na construção histórica de uma escola no contexto brasileiro, que demanda grandes investimentos na qualificação da escola pública e, portanto, não se trata de obstáculos que se associam exclusivamente à educação especial.

\section{Considerações finais}

As reflexões apresentadas visam a ampliar as discussões relativas ao AEE como dispositivo pedagógico, mostrando as diversas configurações que este serviço de apoio pode ser disponibilizado, evidenciando, assim, possibilidades de avanço na organização pedagógica do ambiente escolar.

Ao voltarmos nossas lentes para algumas diretrizes e para dispositivos normativos que versam sobre o AEE, observamos que estes inicialmente direcionam o entendimento que o espaço da sala de recursos seria o lócus prioritário para o atendimento dos alunos público-alvo da educação especial, tendo o professor de educação especial como protagonista nesta prática pedagógica. A Resolução no 04/2009, nos incisos I, II, III e VII, indica que o AEE ocorre na sala de recursos. Contudo, os incisos IV, VI e VIII destacam este atendimento como uma prática pedagógica arti- 
culada a outros espaços escolares, o que evidencia um afastamento da ideia de sala de recursos como espaço prioritário ou exclusivo.

Partindo dessas considerações, as reflexões apresentadas visam a ampliar as discussões relativas ao AEE como dispositivo pedagógico, mostrando as diversas configurações que este serviço de apoio pode ser disponibilizado ao público-alvo da educação especial. Trata-se de uma perspectiva que se opõe à compreensão restrita às práticas educacionais em sala de recursos e que valoriza a pluralidade prevista no plano das proposições e diretrizes políticas. Assim, esse serviço evidencia novas possibilidades de organização, sendo algumas delas: assumir um caráter descentralizado, ocorrer em todos os espaços escolares, não se restringir a um conjunto de instrumentos. Ao observarmos o crescente número de matrículas dos alunos público-alvo da educação especial entre os anos de 2008 e 2020 nas escolas de ensino comum, evidenciamos a necessidade de ampliar a prática do AEE para outros espaços do ambiente escolar com a atuação colaborativa envolvendo a articulação do professor de educação especial e o professor de ensino comum. O trabalho compartilhado tem como premissa básica a reafirmação de que a sala comum é o espaço prioritário para escolarização, rompendo com a lógica de padronização de processos de ensino aprendizagem e as barreiras do espaço escolar. A atuação sistêmica do professor de educação especial, articulada com os profissionais de apoio, com a família, com o serviço de orientação, de supervisão e de gestão deve se estabelecer no cotidiano escolar. Essa rede de serviços objetiva a permanência e o sucesso dos alunos público-alvo da educação especial na escola de ensino comum. Atuando como articulador dos processos educacionais, segundo as bases de uma perspectiva educacional inclusiva, é importante considerar que o professor de educação especial deve agir de forma contextual, porque trabalha com fenômenos complexos, multideterminados, reconhecendo que as limitações de cada aluno são resultantes de um histórico de interações com o meio social. As possibilidades de mudanças previstas em um percurso educacional se multiplicam se nossa ação incide sobre esse meio social que é o contexto escolar.

É necessário aprofundar o estudo sobre o AEE, tendo como foco de análise as diretrizes e normativas que o instituíram. Observamos que alguns aspectos que estão contemplados nesses instrumentos, como a atuação colaborativa com os diferentes segmentos da escola foram secundarizados por muitos atores envolvidos nesse processo. Evidenciamos a necessidade de ampliar as discussões relativas a essa proposta em suas diversas possibilidades de se apresentar e se efetivar nas escolas apontando práticas de atuação colaborativa entre o professor regente de classe e o professor de educação especial.

\section{Referências}

BALL, Stephen. Education reform: a critical and post-structural approach. Buckingham: Open University Press, 1994.

BAMPI, Luciana Neves da Silva; GUILHERM, Dirce; ALVES, Elioenai Dornelles. Modelo social: uma nova abordagem para o tema deficiência. Rev. Latino-Am. Enfermagem [internet], v. 18, n. 4, jul./ago. 2010. Disponível em: https://www. scielo.br/pdf/rlae/v18n4/pt_22.pdf. Acesso em: 13 maio 2021.

BAPTISTA, Claudio Roberto. Ação Pedagógica e Educação Especial: a Sala de Recursos como prioridade na oferta de serviços especializados. Rev. Bras. Ed. Esp., Marília, v. 17, p. 59-76, maio/ago. 2011. [Edição Especial].

BATESON, Gregory. Mente e natureza. Tradução de Cláudia Gerpe. Rio de Janeiro: Francisco Alves, 1986.

BRASIL. Constituição da República Federativa do Brasil. Brasília: Imprensa Oficial, 1988. Brasília, DF: Senado, 1988. Disponível em: http://www.planalto.gov.br. Acesso em: 20 abr. 2021.

BRASIL. Política Nacional de Educação Especial. Brasília, DF: MEC: SEESP, 1994.

BRASIL. LDBEN 9.394, de 20 de dezembro de 1996. Estabelece as Diretrizes e Bases da Educação Nacional. Brasília, DF: MEC: INEP, 1996. Disponível em: http://portal.mec.gov.br. Acesso em: 17 abr. 2021. 
BRASIL. Programa Educação Inclusiva: direito à diversidade/Documento Orientador. Brasília, DF: MEC: SEESP, 2003. Disponível em: http//www.mec.gov.br. Acesso em: 17 abr. 2021.

BRASIL. Portaria normativa $n^{\circ}$ 13, de 24 de abril de 2007. Dispõe sobre a criação do Programa de Implantação de Salas de Recursos Multifuncionais. Brasília, DF: MEC, 2007. Disponível em: http://portal.mec.gov.br. Acesso em: 17 abr. 2021.

BRASIL. Política Nacional de Educação Especial na Perspectiva da Educação Inclusiva. Brasília, DF: MEC: SEESP, 2008.

BRASIL. Decreto $n^{\circ}$ 6.949, de 25 de agosto de 2009. Promulga a Convenção Internacional sobre os Direitos das Pessoas com Deficiência e seu Protocolo Facultativo, assinados em Nova York, em 30 de março de 2007. Diário Oficial da União, República Federativa do Brasil, Brasília, DF: MEC, 2009a. Disponível em: http://www.planalto.gov.br. Acesso em: 17 abr. 2021.

BRASIL. Resolução no 4, de 2 de outubro de 2009. Institui Diretrizes Operacionais para o Atendimento Educacional Especializado na Educação Básica, modalidade Educação Especial. Diário Oficial da União Brasília, DF: MEC: CNE: CEB, 5 de outubro de 2009, 2009b.

BRASIL. Decreto $n^{\circ} 7.611$, de 17 de novembro de 2011. Dispõe sobre a educação especial, o atendimento educacional especializado e dá outras providências. Brasília, DF, 2011.

BRASIL. Nota Técnica No 04, de 23 de janeiro de 2014. Orientação quanto a documentos comprobatórios de alunos com deficiência, transtornos globais do desenvolvimento e altas habilidades/superdotação no Censo Escolar. Brasília, DF: MEC: SECADI: DPEE, 2014b. Disponível em: http://portal.mec.gov.br. Acesso em: 17 abr. 2021.

BRASIL. Lei $n^{\circ}$ 13.146, de 06 de julho de 2015, Institui a Lei Brasileira de Inclusão da Pessoa com Deficiência (Estatuto da Pessoa com Deficiência). Brasília, DF, 2015. Disponível em: http://www.planalto.gov.br. Acesso em: 17 abr. 2021.

CALDEIRA, Maria Carolina da Silva; OLIVEIRA, Elânia de; ARAÚJO, Camila Camilozzi Alves Costa de Albuquerque. Pensar a educação inclusiva no contexto da pesquisa na educação básica: reflexões sobre as ações implementadas pelo Centro Pedagógico da UFMG. Cadernos do Aplicação, Porto Alegre, v. 33, n. 1, jan./jun. 2020. Disponível em: https:// seer.ufrgs.br/CadernosdoAplicacao/article/view/103183. Acesso em: 21 abr. 2021.

HAAS, Clarissa. Narrativas e Percursos Escolares de Jovens e Adultos com Deficiência: "Isso me lembra uma história!". 2013. 240 f. Dissertação (Mestrado) - Universidade Federal do Rio Grande do Sul, UFRGS, Porto Alegre, 2013.

MAINARDES, Jeferson. Abordagem do Ciclo de Políticas: uma contribuição para a análise de políticas educacionais. Educ. Soc., Campinas, v. 27, n. 94, p. 47-69, jan./abr. 2006. Disponível em: https://www.scielo.br/pdf/es/v27n94/ a03v27n94.pdf. Acesso em: 20 abr. 2021.

MENDES, Enicéia Gonçalves. Colaboração entre ensino regular e especial: o caminho do desenvolvimento pessoal para a inclusão escolar. In: MANZINI, Eduardo José (org.). Inclusão e acessibilidade. Marília: ABPEE, 2006. p. 29-41.

MORIN, Edgar. Introdução ao pensamento complexo. 3. ed. Porto Alegre: Sulina, 2007.

PEIXOTO, Joana. A inovação pedagógica como meta dos dispositivos de formação a distância. EccoS - Revista Científica, São Paulo, v. 10, n. 1, p. 39-54, jan./jun. 2008. Disponível em: https://www.redalyc.org/pdf/715/71510103.pdf. Acesso em: 19 abr. 2021.

PISTÓIA, Lenise Henz Caçula. Gregory Bateson e a educação: possíveis entrelaçamentos. 2009. 191 f. Tese (Doutorado em Educação) - Faculdade de Educação, UFRGS. Porto Alegre, 2009.

UNESCO. Declaração de Salamanca: sobre Princípios, Políticas e Práticas na Área das Necessidades Educativas Especiais. Espanha, 1994.

UNESCO. Declaração Mundial de Educação para Todos. Plano de ação para satisfazer as necessidades básicas de aprendizagem. Tailândia, 1990.

VASCONCELLOS, Maria José Esteves. Pensamento Sistêmico: o novo paradigma da ciência. 10. ed. Ver. e atual., Campinas: Papirus, 2013.

Data de submissão: 14/05/2021

Data de aceite: 20/06/2021 